\title{
The utility of the microcoulomb as a predictor of reinforcement value in electrical self-stimulation of the rat brain'
}

JOHN E. RIDGWAY, STANLEY S. PLISKOFF AND ROGER W. MCINTIRE

UNIVERSITY OF MARYLAND

\begin{abstract}
Abstraet
In this experiment, the dependent variable was rate of responding in the initial member of a two member chain, for reinforcement in the second; Pliskoff et al (1965). The reinforcer was a single sine wave stimulus, delivered to the Medial Forebrain Bundle through a bipolar platinum electode. The experimental design was $\begin{array}{llllllll} & 3 & \times & 3 & \times & 3 & \text { factorial. Three combinations of }\end{array}$ amplitude (measured in peak to peak microamperes) and duration were chosen, such as to produce a constant charge in peak to peak microcoulombs, for each combination. Three frequencies (measured in cycles per second) were also used. The amplitude-duration dimension was identified as $\mathrm{A}$, the frequency dimension as B. Ss were identified as c. Significant main effects were found for $\mathrm{A}$ and $\mathrm{B}$, and the A $\times$ B interaction was also significant. These results were interpreted as support for the view that with the charge of the stimulus constant, variance in reward value may yet appear to a significant degree, depending upon the values of the parameters, duration and amplitude.

\section{Problem}

It has been frequently suggested, in and out of print, that what is really important in determining reinforcement value of an electrical stimulus is charge, measured in microcoulombs. Ward (1959) found that the longer a square pulse duration, the greater the charge required to achieve threshold. Keesey (1962) found evidence to suggest that rate of responding can be expressed as a function of the 'quantity of electricity' (charge).

The present study is a direct test of the proposition that changes in response-rate (from this we may infer reinforcement value) produced by manipulating the duration or amplitude of the reinforcing stimulus, may be largely accounted for by changes in the charge of the stimulus.
\end{abstract}

\section{Method}

The apparatus consisted of an experimental box, constructed on all sides but the back of clear plexiglass, the back being made of black plexiglass, and serving as the mounting for a fixed, and a retractable lever. The box was 12 in wide $x 9$ in high, $x 12$ in deep, and was placed in a 14 in $\times 14$ in $\times 26$ in sound attenuation chamber. The electrical stimulus was provided by an Eico sine wave generator, and monitored on an oscilloscope arranged as a microammeter.
Each $S$ was trained to press the fixed lever on the left programmed on a V I 30 sec. schedule to cause the second retractable lever to be inserted into the box. By pressing this second lever, $S$ could obtain a single stimulus, before it retracted. The rats were initially naive, male albinos, of Wistar strain, and were stereotaxically implanted under Nembutal anesthesia, with chronic bipolar platinum electrodes. Accuracy of placement in the Medial Forebrain Bundle was verified histologically.

The experimental design was a $3 \times 3 \times 3$ factorial, identified as $\mathrm{A} \times \mathrm{B} \times \mathrm{C}$

$A_{1} 1,000$ millisec. at 80 microamp. $=80$ microcoul.

$A_{2} 500$ millisec. at 160 microamp. $=80$ microcoul.

$A_{3} 100$ millisec. at 800 microamp. $=80$ microcoul.

$\mathrm{B}_{1} \quad 20 \mathrm{cps}$

$\mathrm{B}_{2} \quad 500 \mathrm{cps}$

$\mathrm{B}_{3} 2,000 \mathrm{cps}$

Each $\mathrm{S}$ was run under all of the nine possible combinations of parameters, one per day per rat. Each daily session was run as follows; the parameters were chosen randomly from those specified by the design. The stimulator was calibrated, and the trained animal placed in the experimental box to work for a $300 \mathrm{sec}$. warm-up period. During this time the stimulator was adjusted to compensate for changes in brain tissue impedance due to stimulation. After $300 \mathrm{sec}$. the Experimental session of 3,000 sec. commenced automatically. Mean rates of responding on the $V I$ schedule, during these sessions, were the data.

\section{Results and Diseussion}

There were significant main effects for both the $A$ and $B$ dimensions; in addition the $A \times B$ interaction was significant. (A, $F=5.4629 ; \quad p<0.05 ; \quad B, F=7.7266$; $\mathrm{p}<0.05 ; \mathrm{A} \times \mathrm{B}, \mathrm{F}=4.2039$; $\mathrm{p}<0.05$.) A graphical summary of the results is to be found in Fig. 1.

The rationale for the constancy of the A dimension, is of course that if charge is held constant while duration and amplitude vary, then if solely effective in determining rate of responding, there should be no significant difference within $A$. The fact that such a difference exists in the present data, points up the limitations that must be imposed upon simplifying para- 


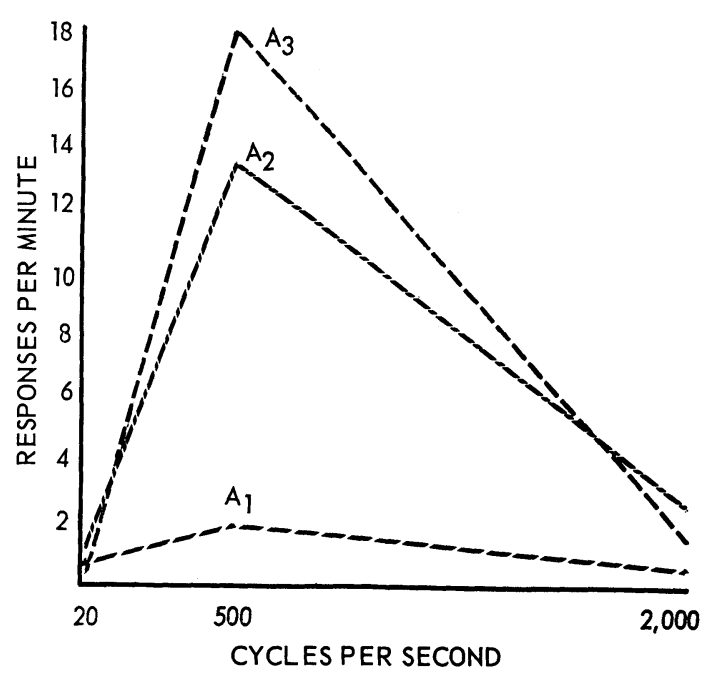

Fig. 1.

metric concepts of the coulomb type. The B dimension provides a demostration of the results of varying frequency; a curvilinear relationship seems to exist with rate of responding. It will be noted that the range in which high rates of responding occur, is quite small. The main reason for varying frequency in this experiment, was not however to examine a functional relationship, but to seek an interaction. Clearly, if there is nothing varying in $A$ there can be no interaction with $B$. The presence of a significant A $x$ B interaction, is additional evidence in favor of the suggestion that there is variance in $A$, not accounted for by changes in charge.

In summary, it is suggested that if significant differences in rate of responding may be obtained under conditions of constant frequency and charge, using a design of limited statistical power, it would seem reasonable to conclude that stimuli should be specified in terms of amplitude and duration, and that the microcoulomb is no substitute for such specification, and no accurate indicator of magnitude of reinforcement.

\section{Relerences}

Keesey, Richard $\mathbf{E}$. The relation between pulse frequency, intensity, and the rate of responding for intracranial stimulation. J. comp. physiol. Psychol., 1962, 55, 671-678.

McIntire, R. W., \& Wright, J. E. Parameters related to responserate for septal and medial forebrain bundle stimulation. J. comp. physiol. Psychól., 1965, 59, 131-134.

Pliskoff, S. S., Wright, J. E., \& Hawkins, T. D. Brain stimulation as a reinforcer: Intermittent schedules. J. exp. Anal. Behav., $1965,8,75-88$.

Uyeda, A. H., \& Gegerelli, J. A. Influences of rectangular pulses and sine waves of varying frequencies on brain self-stimulation in the laboratory rat. Psychol. Rep., 1959, 5, 641-647.

Ward, Henry P. Stimulus factors in septal self-stimulation. Amer. J. Physiol., 1959, 196, 779-782.

Note

1. This research constitutes part of a dissertation by the senior author. The work was supported by contract No. DA-49-193-MD2288, between the Office of the Surgeon General, U. S. Army, and the University of Maryland.

\section{Comment}

Surridge \& Amsel (1965), consistent with Amsel, MacKinnon, Rashotte \& Surridge (1964), conclude that massed and spaced trial patterning is contaminated or regulated by visual, olfactory, or auditory cues. Perhaps so. But available evidence fails to support the contention and much opposes it. Fairness dictates that the erroneous impression fostered by Amsel and his associates be corrected.

If small or vision regulated patterning it would be expected that running would be slower on nonrewarded (N) than on rewarded (R) trials under any reward schedule. Early investigations by the writer and others routinely included a "randomly" rewarded group which, unlike single alternation (SA), showed no tendency to pattern. Figure 1 of a later study by Bloom \& Capaldi (1961) clearly shows that while SA patterned, DA (double alternation) ran as rapidly on $N$ as on $R$ trials and as rapidly as SA on R. Later when SA was shifted to DA, as predicted, running continued to be slow following $\mathbf{R}$, fast following N. Note, running was now slow on half the $R$ trials and fast on half the $\mathrm{N}$ trials, rather foolish behavior if the presence or absence of food could be seen, smelled, or heard. Capaldi \& Senko (1962) showed that when a $R$ trial follows two successive $N$ trials $\left(N_{1} N_{2} R\right)$, as predicted, running was slow on $N_{1}$, rapid and nondifferential on $\mathrm{N}_{2}$ and $\mathrm{R}$. Presumably, $\mathrm{N}_{1}$ and $\mathrm{N}_{2}$ smell and look the same, and since the position of the food is changed on $\mathrm{N}_{1}$ and $R$ these sound the same. These data invite Amsel et al to be specific rather than general in their conclusions.

Aside from food under the goal box, Surridge \& Amsel's procedure differed in many particulars from Capaldi \& Spivey (1964), but unaccountably none of these differences is mentioned by them as a possible basis for the discrepant findings. Concerning one difference between investigations, published information is actually available. Burt \& Wike (1963), employing three SA groups, showed that N-trial running is slower and develops sooner, the longer the confinement on $\mathbf{N}$

(Continued on page 132) 